\section{Cureus}

Received 05/18/2018

Review began 05/27/2018

Review ended 06/16/2018

Published 06/25/2018

C) Copyright 2018

Saleem et al. This is an open access article distributed under the terms of the Creative Commons Attribution License CC-BY 3.0., which permits unrestricted use, distribution, and reproduction in any medium, provided the original author and source are credited.

\title{
Management of Upper Gastrointestinal Bleeding by an Internist
}

\author{
Saad Saleem ${ }^{1}$, Abell L. Thomas ${ }^{2}$ \\ 1. Internal Medicine, Mercy St. Vincent Medical Center, Toledo, USA 2. Gastroenterology, University of \\ Louisville, Louisville, USA
}

$\square$ Corresponding author: Saad Saleem, saadsaleem29@gmail.com

Disclosures can be found in Additional Information at the end of the article

\section{Abstract}

Nonvariceal upper gastrointestinal bleeding (UGIB) carries high morbidity and mortality, which can be lowered by timely evaluation and management. This article presents a comprehensive literature review and current guidelines for the management of nonvariceal UGIB by an internist. Pre-endoscopic management includes optimal resuscitation, and making a decision about holding the anticoagulation and antiplatelet therapy versus continuation due to risk of thrombosis. Proton pump inhibitors (PPIs) are beneficial for both ulcer and nonulcer diseases as they reduce the risk of re-bleeding by clot stabilization. Endoscopy should only be performed after hemodynamic stability has been achieved and should not be delayed by more than 24 hours. Resumption of anticoagulation and antiplatelet therapy is based on endoscopic findings and thromboembolic risk. The patient should be discharged on PPIs and should be followed up by a primary care physician.

Categories: Family/General Practice, Internal Medicine, Gastroenterology

Keywords: upper gi, gastrointestinal bleed, internist

\section{Introduction And Background}

Upper gastrointestinal bleeding (UGIB) is defined as a clinically significant bleeding (no fixed amount of blood) from the gastrointestinal (GI) tract above the ligament of Treitz (anatomical landmark between the duodenum and jejunum) which includes the esophagus, stomach, and duodenum. The patient usually shows signs of bleeding in the GI tract either as hematemesis (vomiting of bright red blood or coffee ground emesis) or melena (black tarry stools). The majority of melena (black, tarry stool) originates proximal to the ligament of Treitz (90\%), though it may as well arise from the oropharynx or nasopharynx, small bowel, or right colon [1].

Melena may be seen in varying stages of blood loss, with as little as $50 \mathrm{ml}$ of blood [2]. Hematemesis (vomiting of bright red blood) is suggestive of moderate to severe bleeding, whereas coffee ground emesis (oxidation of the heme molecule of red blood cells due to gastric acid) suggests more limited bleeding. The yearly incidence of hospitalization for acute UGIB is about 100 per 100,000 people [3]. The UGIB rate of admission to the hospital is six times higher as compared to lower GI bleeding [3].

Although the diagnosis and management of nonvariceal UGIB has improved over time, it still results in 400,000 hospital admissions per year, costing more than two billion dollars per year [4]. Despite advances in therapy, hospital mortality resulting from UGIB remains high, which can be lowered by proper evaluation and management. The reported frequencies of specific causes have changed over time. Peptic ulcer disease constitutes roughly $20 \%-25 \%$ of 
cases as compared to older studies when it used to constitute half of UGIB [5-7]. The most common causes of UGIB include the following (in approximate descending order of frequency) [5-6, 8-10]: gastric and/or duodenal ulcers, esophagogastric varices, severe or erosive esophagitis, severe or erosive gastritis/duodenitis, portal hypertensive gastropathy, angiodysplasia (also known as vascular ectasia), mass lesions (polyps/cancers), Mallory-Weiss syndrome, and no lesion identified (10\%-15\% of patients).

The source of bleeding cannot be recognized in 10\%-15\% of patients with UGIB; either the lesion is hard to identify (such as a Dieulafoy's lesion), obscured by a retained blood clot at endoscopy, or the lesion has already healed by the time endoscopy was performed. The four major risk factors for bleeding peptic ulcers are [11-12]: Helicobacter pylori (H. pylori) infection, use of nonsteroidal anti-inflammatory drugs (NSAIDs), physiologic stress, and excess gastric acid.

\section{Review}

\section{Pre-endoscopy management}

Patients are triaged based on hemodynamic status, age, comorbidities, and initial lab results. The first and foremost step in the management of UGIB is assessing the hemodynamic status and starting a resuscitative measure. In acute UGIB, hemoglobin is not a good indicator for estimating GI blood loss. The patient should receive intravenous (IV) isotonic fluids, and transfusion should be given maintaining the hemoglobin at a level $\geqslant 7 \mathrm{~g} / \mathrm{dl}(70 \mathrm{~g} / \mathrm{l})$ or above if the patient is symptomatic [13].

Risk assessment regarding further GI bleeding and mortality will determine decisions regarding level of care, timing of endoscopy, and discharge planning. Main scores are the Blatchford score, Rockall score, and AIMS65. These scores are used to identify patients with UGIB who need to be admitted to the hospital, as the bleeding requires further medical intervention such as a blood transfusion or an endoscopic intervention. The Blatchford score as compared to the Rockall score does not take endoscopic findings into account, so it can be calculated after the patient comes to the emergency room. This score is based upon the blood urea nitrogen, hemoglobin, systolic blood pressure, pulse and presence of melena, syncope, hepatic disease, and/or cardiac failure. The score ranges from 0 to 23 , and the chances of requiring an endoscopic intervention increases with a higher score. Meta-analysis has shown that a score of 0 was associated with a low likelihood of needing an endoscopic intervention [14].

The AIMS65 studies have suggested that it has a high accuracy for predicting inpatient mortality among patients with UGIB. It was derived from a database of 187 US hospitals [15]. Studies have shown that an increasing score is associated with higher mortality and a prolonged stay in the hospital. The study found that five factors were associated with increased inpatient mortality [15]: albumin less than $3.0 \mathrm{~g} / \mathrm{dl}$ (30 g/l), international normalized ratio (INR) greater than 1.5, altered mental status, systolic blood pressure of $90 \mathrm{mmHg}$ or less, and age older than 65 years.

Anticoagulation and antiplatelet therapy should be performed for patients with UGIB. However, the risk of thrombosis should be weighed against the risk of bleeding. Anticoagulation should be reversed in case of acute hemorrhage. If a patient taking warfarin and INR is supratherapeutic, fresh frozen plasma (FFP) or prothrombin complex concentrate should be given. There is no antidote for most of the newer anticoagulation agents, but they have a short half-life in the presence of normal kidney function. These medications should be held and bleeding will likely stop in the next 12-24 hours [16]. A small study (conducted in 1994) that included 52 patients showed successful hemostasis after endoscopic therapy in $91 \%$ of patients after correcting the INR to 1.5-2.5 compared to the control population who were not 


\section{Cureus}

anticoagulated [17].

Proton pump inhibitors (PPIs) should be started in patients admitted with UGIB until the source of bleeding is identified. It is beneficial in both ulcer and nonulcer diseases. A high-dose intravenous infusion of PPI reduces the risk of re-bleeding ulcers [18]. It promotes hemostasis by neutralizing gastric acid, which leads to clot stabilization [19]. Gastroenterology service should be involved in all the patients with significant UGIB. There is data supporting the use of IV erythromycin before endoscopy. It improves visualization of the stomach by moving the blood and food particles from the stomach [20], thereby increasing the chances of visualizing the bleeding vessel. It reduces the need for a second-look endoscopy.

The patient's discharge to home directly from the emergency room (ER) without inpatient endoscopy may be considered if urea nitrogen $<18.2 \mathrm{mg} / \mathrm{dl}$, hemoglobin greater than or equal to $13 \mathrm{~g} / \mathrm{dl} \mathrm{for} \mathrm{men} \mathrm{and} 12 \mathrm{mg} / \mathrm{dl}$ for women, systolic blood pressure greater than or equal to 110 $\mathrm{mmHg}$, pulse $<100 / \mathrm{min}$, absence of melena, syncope, cardiac failure, and liver disease as they have less than one percent chance of requiring intervention [13]

\section{Upper endoscopy}

Endoscopy should be performed in a nonemergent setting. Patients should be hemodynamically stabilized and should undergo an endoscopy within 24 hours of admission [13]. If the patient is hemodynamically stable on admission and does not have serious comorbidities, an endoscopy should be performed as soon as possible [13]. Patients with endoscopic findings of high-risk stigmata (Table 1) (active bleeding, visible vessel, clots) should be hospitalized for three days assuming no further episode of bleeding occurs. They can be fed with clear liquids soon after endoscopy [13]. Clear liquids provide the advantage that if the patient starts to bleed again, sedation and anesthesia can be given within two hours after the last ingestion [21]. Patients with clean-based ulcers can be discharged home if they have a residence and someone can observe them [13].

\begin{tabular}{|c|c|c|}
\hline Endoscopic stigmata of recent hemorrhage & Prevalence (\%) & Risk of re-bleeding on medical management (\%) \\
\hline Active arterial bleeding (Forrest la) & 10 & 90 \\
\hline Oozing without visible vessel (Forrest lb) & 10 & $10-20$ \\
\hline Non-bleeding visible vessel (Forrest Ila) & 25 & 50 \\
\hline Adherent clot (Forrest Ilb) & 10 & $25-30$ \\
\hline Flat spot (Forrest IIc) & 10 & $7-10$ \\
\hline Clean ulcer base (Forrest (III) & 35 & $3-5$ \\
\hline
\end{tabular}

\section{TABLE 1: Endoscopic predictors of recurrent peptic ulcer hemorrhage}




\section{Cureus}

days (clopidogrel), three to five days (ticagrelor), seven days (prasugrel), or 10-14 days (ticlopidine) [23-25]. Stopping P2Y12 platelet receptor blockers should also be considered in patients at high risk for thromboembolic complications who are undergoing high-risk procedures, if the risk of bleeding is thought to outweigh the risk of thromboembolism. Aspirin need not be discontinued. A cardiologist or a neurologist should be consulted based on the indication of the antiplatelet therapy.

\section{Higher-risk procedures}

Polypectomy

Biliary or pancreatic sphincterotomy

Treatment of varices

PEG placement

Therapeutic balloon-assisted enteroscopy

EUS with FNA

Endoscopic hemostasis

Tumor ablation

Cystogastrostomy

Ampullary resection

EMR

Endoscopic submucosal dissection

Pneumatic or bougie dilation

PEJ

Low-risk procedures

Diagnostic (EGD, colonoscopy, flexible sigmoidoscopy) including mucosal biopsy

ERCP with stent (biliary or pancreatic) placement or papillary balloon dilation without sphincterotomy

Push enteroscopy and diagnostic balloon-assisted enteroscopy

Capsule endoscopy

Enteral stent deployment (controversial)

EUS without FNA

Argon plasma coagulation

Barrett's ablation

TABLE 2: The management of antithrombotic agents for patients undergoing gastrointestinal endoscopy 


\section{Cureus}

Abbreviations: EGD, esophagogastroduodenoscopy; ERCP, endoscopic retrograde cholangiopancreatography; PEG, percutaneous endoscopic gastrostomy; EUS, endoscopic ultrasound; FNA, fine-needle aspiration; EMR, endoscopic mucosal resection; PEJ, percutaneous endoscopic jejunostomy [26]

The American Society of Gastrointestinal Endoscopy (ASGE) guidelines recommend avoiding elective procedures on cardiac stents patients until they has received antithrombotic therapy for the minimum recommended duration based upon the current guidelines [26]. Once beyond that period, depending on the type of stent used, P2Y12 platelet receptor blockers are discontinued 5-14 days prior to the procedure, while continuing aspirin. The guidelines recommend that patients who are within six weeks of bare-metal stent placement or within six months of drug-eluting stent placement have surgical procedures deferred, if possible, until this period [26]. After the procedure, the P2Y12 platelet receptor blocker should be restarted, with or without a loading dose, as soon as it is considered safe, depending on the patient's indication for taking it and any intervention performed during the endoscopy that may increase the risk for bleeding (such as removal of a large polyp) [27].

\section{Post-endoscopy}

Data are limited about resumption of anticoagulation after achieving endoscopic hemostasis, but studies have shown that resuming anticoagulation has better outcomes than not resuming. Unfractioned heparin is preferred for bridge therapy due to a shorter half-life of 1.5 hours [26]. After endoscopy, the patient should be followed up for the results of $H$. pylori. Patients with $H$. pylori associated bleeding ulcers should receive $H$. pylori therapy. Once the eradication is documented, they do not require long-term antisecretory therapy [13]. A patient who develops NSAID-associated ulcers should be carefully assessed. If needed to be resumed, the lowest dose cyclooxygenase-2 (COX-2) selective NSAID with daily PPI is recommended [13]. If the patient develops low-dose aspirin-induced ulcers, aspirin has to be stopped if given for primary prevention of cardiovascular disease. It can be continued if given for secondary prevention of cardiovascular diseases with long-term use of PPI. Aspirin can be resumed between three and seven days after UGIB [13]. The PPI should be continued in the long term if the gastric ulcer is idiopathic. Aspirin and other NSAIDS given alone in standard doses do not increase the risk of bleeding after an upper endoscopy with biopsy or biliary sphincterotomy [28-31].The data are conflicting about whether aspirin or/and NSAIDS increase the risk of bleeding postpolypectomy.

The 2010 International Consensus Recommendations do not recommend routine use of a second-look endoscopy for nonvariceal UGIB [32]. The guidelines suggest that patients at a particularly high risk for recurrent bleeding may benefit from a second-look endoscopy; these patients include those whose first endoscopy was limited or if the first endoscopic therapy was suboptimal.

A physician should monitor the patients for the following which may suggest re-bleeding [33]: hematemesis more than six hours after the initial endoscopy, melena after normalization of stool color, hematochezia after normalization of stool color, development of tachycardia (heart rate $\geqslant 110$ beats per minute) or hypotension (systolic blood pressure $\leqslant 90 \mathrm{mmHg}$ ) after one hour of hemodynamic stability in the absence of other possible alternatives, hemoglobin drop of 2 $\mathrm{g} / \mathrm{dl}$ or more after two consecutive stable hemoglobin values with at least three hours difference, and tachycardia or hypotension that does not resolve within eight hours. Patients with signs of recurrent bleeding following first endoscopic therapy are typically treated with a second endoscopic therapy. 
Physicians should be diligent in avoiding the complications associated with endoscopy. Complications are more common with emergent endoscopy [34]. It includes aspiration pneumonitis, hypoventilation due to oversedation, or hypotension due to inadequate volume replacement in addition to sedation with opiates. Postoperative complications include perforation of the esophagus leading to mediastinitis; epinephrine injections can cause tachycardia and arrhythmias [34].

Long-term use of PPI has been associated with several side effects. Its use has been associated with increased risk of Clostridium difficile infection in the absence of antibiotic use [35,36]. Its use has been associated with microscopic colitis, including lymphocytes and collagenous colitis [37]. PPI can increase the risk of fractures. Induced hypochlorhydria can augment osteoclastic activity, thereby decreasing bone density [38]. PPI can cause acute interstitial nephritis [39]. Patients should follow up with a primary care physician after discharge to decide about PPI.

\section{Conclusions}

Upper GI bleeding is a medical emergence with high mortality which can be lowered by proper assessment and management. A validated scoring system can help the internist decide about the level of care, timing of endoscopy, and discharge planning. The risk of thrombosis ought to be weighed against the risk of bleeding before holding the anticoagulation and antiplatelet therapy in UGIB. Endoscopy should be performed after hemodynamically stabilizing the patient. It should be performed within 24 hours of admission. Data are restricted about resumption of anticoagulation after accomplishing endoscopic hemostasis. It should be individually based on anticoagulation indication and on endoscopic findings. In spite the fact that PPI utilization brings down the risk of re-bleeding, long-term use of PPI should be justified considering the side effects related with it.

\section{Additional Information \\ Disclosures}

Conflicts of interest: In compliance with the ICMJE uniform disclosure form, all authors declare the following: Payment/services info: All authors have declared that no financial support was received from any organization for the submitted work. Financial relationships: All authors have declared that they have no financial relationships at present or within the previous three years with any organizations that might have an interest in the submitted work. Other relationships: All authors have declared that there are no other relationships or activities that could appear to have influenced the submitted work.

\section{References}

1. Cappell MS, Friedel D: Initial management of acute upper gastrointestinal bleeding: from initial evaluation up to gastrointestinal endoscopy. Med Clin North Am. 2008, 92:491. 10.1016/j.mcna.2008.01.005

2. Doherty GM: Current Diagnosis and Treatment: Surgery, 13th Ed. Loeb MS, Davis K (ed): McGraw-Hill Companies, USA; 2010. p. 493.

3. Longstreth GF: Epidemiology of hospitalization for acute upper gastrointestinal hemorrhage: a population-based study. Am J Gastroenterol. 1995, 90:206.

4. Lanas A, Perez-Aisa MA, Feu F, et al.: A nationwide study of mortality associated with hospital admission due to severe gastrointestinal events and those associated with nonsteroidal antiinflammatory drug use. Am J Gastroenterol. 2005, 100:1685. 10.1111/j.15720241.2005.41833.x

5. Boonpongmanee S, Fleischer DE, Pezzullo JC, et al.: The frequency of peptic ulcer as a cause of upper-GI bleeding is exaggerated. Gastrointest Endosc. 2004, 59:788. 10.1016/S00165107(04)00181-6 
6. Enestvedt BK, Gralnek IM, Mattek N, Lieberman DA, Eisen G: An evaluation of endoscopic indications and findings related to nonvariceal upper-GI hemorrhage in a large multicenter consortium. Gastrointest Endosc. 2008, 67:422. 10.1016/j.gie.2007.09.024

7. Loperfido S, Baldo V, Piovesana E, et al.: Changing trends in acute upper-GI bleeding: a population-based study. Gastrointest Endosc. 2009, 70:212-224. 10.1016/j.gie.2008.10.051

8. Balderas V, Bhore R, Lara LF, Spesivtseva J, Rockey DC: The hematocrit level in upper gastrointestinal hemorrhage: safety of endoscopy and outcomes. Am J Med. 2011, 124:970976. 10.1016/j.amjmed.2011.04.032

9. Wollenman CS, Chason R, Reisch JS, Rockey DC: Impact of ethnicity in upper gastrointestinal hemorrhage. J Clin Gastroenterol. 2014, 48:343-350. 10.1097/MCG.0000000000000025

10. Lee YT, Walmsley RS, Leong RW, Sung JJ: Dieulafoy's lesion. Gastrointest Endosc. 2003, 58:236-243. 10.1067/mge.2003.328

11. Hunt RH, Malfertheiner P, Yeomans ND, Hawkey CJ, Howden CW: Critical issues in the pathophysiology and management of peptic ulcer disease. Eur J Gastroenterol Hepatol. 1995, 7:685-699.

12. Hallas J, Lauritsen J, Villadsen HD, Gram LF: Nonsteroidal anti-inflammatory drugs and upper gastrointestinal bleeding, identifying high-risk groups by excess risk estimates. Scand J Gastroenterol. 1995, 30:438-444. 10.3109/00365529509093304

13. Laine L, Jensen DM: Management of patients with ulcer bleeding. Am J Gastroenterol. 2012, 107:345-493. 10.1038/ajg.2011.480

14. Srygley FD, Gerardo CJ, Tran T, Fisher DA: Does this patient have a severe upper gastrointestinal bleed?. J Am Med Assoc. 2012, 307:1072-1079. 10.1001/jama.2012.253

15. Saltzman JR, Tabak YP, Hyett BH, Sun X, Travis AC, Johannes RS: A simple risk score accurately predicts in-hospital mortality, length of stay, and cost in acute upper GI bleeding. Gastrointest Endosc. 2011, 74:1215-1224. 10.1016/j.gie.2011.06.024

16. Desai J, Granger CB, Weitz JI, Aisenberg J: Novel oral anticoagulants in gastroenterology practice. Gastrointest Endosc. 2013, 78:227-239. 10.1016/j.gie.2013.04.179

17. Choudari CP, Rajgopal C, Palmer KR: Acute gastrointestinal haemorrhage in anticoagulated patients: diagnoses and response to endoscopic treatment. Gut. 1994, 35:464-466.

18. Chan WH, Khin LW, Chung YF, Goh YC, Ong HS, Wong WK: Randomized controlled trial of standard versus high-dose intravenous omeprazole after endoscopic therapy in high-risk patients with acute peptic ulcer bleeding. Br J Surg. 2011, 98:640-644. 10.1002/bjs.7420

19. Green FW Jr, Kaplan MM, Curtis LE, Levine PH: Effect of acid and pepsin on blood coagulation and platelet aggregation. A possible contributor prolonged gastroduodenal mucosal hemorrhage. Gastroenterology. 1978, 74:38-43.

20. Frossard JL, Spahr L, Queneau PE, et al.: Erythromycin intravenous bolus infusion in acute upper gastrointestinal bleeding: a randomized, controlled, double-blind trial.

Gastroenterology. 2002, 123:17-23. 10.1053/gast.2002.34230

21. American Society of Anesthesiologists Task Force on Sedation and Analgesia by NonAnesthesiologists: Practice guidelines for sedation and analgesia by non-anesthesiologists . Anesthesiology. 2002, 96:1004-1017.

22. Katschinski B, Logan R, Davies J,et al.: Prognostic factors in upper gastrointestinal bleeding . Dig Dis Sci. 1994, 39:706. 10.1007/BF02087411

23. Baron TH, Kamath PS, McBane RD: Management of antithrombotic therapy in patients undergoing invasive procedures. N Engl J Med. 2013, 368:2113-2124. 10.1056/NEJMra1206531

24. Baron TH, Kamath PS, McBane RD: New anticoagulant and antiplatelet agents: a primer for the gastroenterologist. Clin Gastroenterol Hepatol. 2014, 12:187-195.

10.1016/j.cgh.2013.05.020

25. Boustière C, Veitch A, Vanbiervliet G, et al.: Endoscopy and antiplatelet agents. European Society of Gastrointestinal Endoscopy (ESGE) Guideline. Endoscopy. 2011, 43:445-461. 10.1055/s-0030-1256317

26. ASGE Standards of Practice Committee, Acosta RD, Abraham NS, et al.: The management of antithrombotic agents for patients undergoing GI endoscopy. Gastrointest Endosc. 2016, 83:3-16. 10.1016/j.gie.2015.09.035

27. Becker RC, Scheiman J, Dauerman HL, et al.: Management of platelet-directed pharmacotherapy in patients with atherosclerotic coronary artery disease undergoing elective endoscopic gastrointestinal procedures. J Am Coll Cardiol. 2009, 104:2903-2917. 10.1016/j.jacc.2009.09.012 
28. Cotton PB, Lehman G, Vennes J, et al.: Endoscopic sphincterotomy complications and their management: an attempt at consensus. Gastrointest Endosc. 1991, 37:383-393.

10.1016/S0016-5107(91)70740-2

29. Shiffman ML, Farrel MT, Yee YS: Risk of bleeding after endoscopic biopsy or polypectomy in patients taking aspirin or other NSAIDS. Gastrointest Endosc. 1994, 40:458-462.

10.1016/S0016-5107(94)70210-1

30. Hussain N, Alsulaiman R, Burtin P, et al.: The safety of endoscopic sphincterotomy in patients receiving antiplatelet agents: a case-control study. Aliment Pharmacol Ther. 2007, 25:579-

584. 10.1111/j.1365-2036.2006.03225.x

31. Hamada T, Yasunaga H, Nakai Y, et al.: Bleeding after endoscopic sphincterotomy or papillary balloon dilation among users of antithrombotic agents. Endoscopy. 2015, 47:997-1004. 10.1055/s-0034-1392408

32. Barkun AN, Bardou M, Kuipers EJ, et al.: International consensus recommendations on the management of patients with nonvariceal upper gastrointestinal bleeding. Ann Intern Med. 2010, 152:101-113.

33. Laine L, Spiegel B, Rostom A, et al.: Methodology for randomized trials of patients with nonvariceal upper gastrointestinal bleeding: recommendations from an international consensus conference. Am J Gastroenterol. 2010, 105:540-550. 10.1038/ajg.2009.702

34. Eisen GM, Baron TH, Dominitz JA, et al.: Complications of upper GI endoscopy. Gastrointest Endosc. 2002, 55:784-793. 10.1016/S0016-5107(02)70404-5

35. Naggie S, Miller BA, Zuzak KB, et al.: A case-control study of community-associated Clostridium difficile infection: no role for proton pump inhibitors. Am J Med. 2011, 124:276.e1-7. 10.1016/j.amjmed.2010.10.013

36. Cao F, Chen CX, Wang M, et al.: Updated meta-analysis of controlled observational studies: proton-pump inhibitors and risk of Clostridium difficile infection. J Hosp Infect. 2018, 98:413. 10.1016/j.jhin.2017.08.017

37. Keszthelyi D, Jansen SV, Schouten GA, et al.: Proton pump inhibitor use is associated with an increased risk for microscopic colitis: a case-control study. Aliment PharmacolTher. 2010, 32:1124-1128. 10.1111/j.1365-2036.2010.04453.x

38. Tuukkanen J, Väänänen HK: Omeprazole, a specific inhibitor of $\mathrm{H}^{+-K+-A T P a s e, ~ i n h i b i t s ~ b o n e ~}$ resorption in vitro. Calcif Tissue Int. 1986, 38:123-125.

39. Sampathkumar K, Ramalingam R, Prabakar A, Abraham A: Acute interstitial nephritis due to proton pump inhibitors. Indian J Nephrol. 2013, 23:304-307. 10.4103/0971-4065.114487 